\title{
Microwave electrodeless lamp photolytic degradation of acid orange 7
}

\author{
Xiwang Zhang*, Guoting Li, Yizhong Wang, Jiuhui Qu \\ State Key Laboratory of Environmental Aquatic Chemistry, Research Center for Eco-Environmental Sciences, \\ Chinese Academy of Sciences, P.O. Box 2871, Beijing 100085, China \\ Received 28 September 2005; received in revised form 6 March 2006; accepted 16 March 2006 \\ Available online 30 March 2006
}

\begin{abstract}
Photolytic degradation of acid orange 7 (AO7) under microwave irradiation was investigated in which a novel microwave electrodeless lamp (MWL) was employed as light source. The novel MWL brings a new way to study the simultaneous effect of both UV-vis light and microwave irradiation on degradation of dye pollutants. Color, TOC, $\mathrm{pH}$ and inorganic ions concentrations with reaction time were monitored to evaluate the ability of MWL to degrade AO7. It was found that the coupled UV-vis/microwave irradiation led to excellent performance on decolorization and mineralization. AO7 solution could be completely decolorized at $80 \mathrm{~min}$ and mineralized at 150 min. Inorganic ions produced in the solution proved that AO7 was completely destroyed. The mechanism of MWL photolytic degradation of AO7 was investigated by examining the presence and role of some important oxidative species, such as superoxide $\left(\mathrm{O}_{2}{ }^{\bullet-}\right)$, hydroxyl radical $\left(\mathrm{HO}^{\bullet}\right), \mathrm{H}_{2} \mathrm{O}_{2}$ and $\mathrm{O}_{3}$, using appropriate quenchers. The results showed that a large amount of $\mathrm{H}_{2} \mathrm{O}_{2}$ and $\mathrm{O}_{3}$ could be generated in $\mathrm{AO} 7$ solution by MWL irradiation and the degradation of AO7 was mainly achieved by the attack of $\mathrm{HO}^{\bullet}$ radicals resulted from photolysis of $\mathrm{H}_{2} \mathrm{O}_{2}$ and $\mathrm{O}_{3}$. Direct oxidation of $\mathrm{AO}$ by $\mathrm{O}_{3}$ and $\mathrm{O}_{2}{ }^{\bullet-}$ also played a few roles in degradation of AO7.
\end{abstract}

(C) 2006 Elsevier B.V. All rights reserved.

Keywords: Microwave electrodeless lamp (MWL); Acid orange 7 (AO7); Oxidative species; Mechanism

\section{Introduction}

Microwave is widely used domestically and industrially due to its heating effects on polar substances [1]. Other potential applications of microwave have been recognized and have been applied to a number of useful processes, such as organic and inorganic syntheses, polymerization, analyses and extraction, food sterilization, etc. [2-4]. Recently, microwave irradiation has been used to assist photochemical reactions for the degradation of organic pollutants [1,3-11]. Horikoshi et al. [3] proved that the integrated microwave/photocatalysis method was superior in the degradation of dye Rhodamine- $\mathrm{B}$ to $\mathrm{TiO}_{2}$ photocatalytic degradative method alone. About $20 \%$ more $\mathrm{OH}^{\bullet}$ radicals were found to be generated by photocatalysis with microwave irradiation than photocatalysis alone. Han et al. [5] showed that microwave irradiation could also considerably enhance the oxidative degradation of phenol in the $\mathrm{H}_{2} \mathrm{O}_{2} / \mathrm{UV}$ reacting system even under a suppression of the thermal effect.

\footnotetext{
* Corresponding author. Tel.: +86 1062849145 ; fax: +86 1062923541 .

E-mail address: xiwangzhang@126.com (X. Zhang).
}

Although microwave effectively accelerated photocatalytic or photochemical reaction as shown above, it is inconvenient for conventional electrode lamps to combine with microwave in photochemical reactions because their metal electrodes are easily damaged under microwave irradiation. The problem will be solved if microwave electrodeless lamp (MWL) substitutes the conventional lamp as light source because MWL has no electrodes. MWL comprises an envelope or bulb containing a plasma-forming medium. When it is placed in a microwave energy field the gases within the envelope will ionize, a lowpressure plasma discharge forms, heating and beating the envelope, vaporizing materials within the envelope to emit light. MWL brings a convenient way to study the synergetic effect of UV-vis irradiation and microwave irradiation on photochemical reactions. Comparative experiments in photoinitiated radical addition of tetrahydrofuran to perfluorohexylethene reaction showed that MWL provided a high yield of product in shorter reaction time [4]. Klán [12-14] also confirmed that MWL was feasible in light-induced photofragmentation reaction of valerophenone. More efficient photodegradation of Rhodamine$\mathrm{B}$ and 2,4-dichlorophenoxyacetic acid were found in microwave assisted photocatalytic degradation with MWL (a double quartz 
cylindrical plasma photoreactor) as light source $[6-8,10]$. As illustrated above, MWL will be a prospective tool for microwave photochemistry including photodegradation of contaminants.

Dye pollutants, which are toxic to aquatic biota, can lead to aesthetic problem and eutrophication $[15,16]$. Most of the dyes are resistant to light. Even though under strong UV irradiation, what was found was slow decolorization or mineralization rate [17-21]. However, our researches [22,23] showed that the fast color removal of azo dyes Reactive Brilliant Red X-3B and acid orange 7 (AO7) under MWL irradiation were achieved. This indicated that the coupled UV-vis/microwave irradiation from MWL could accelerate the degradation of organic pollutants. However, the mechanism of photolytic degradation of organic pollutants under MWL irradiation has not been investigated in detail so far. In order to understand the synergetic effect of microwave irradiation and UV-vis irradiation further investigation was necessary.

In this study, AO7 was used as a typical organic pollutant to obtain detailed information of photolytic degradation of dye under MWL irradiation. The ability of MWL to degrade dye was evaluated by monitoring color, TOC, $\mathrm{pH}$ and some final inorganic products in solution. The degradation mechanism was also investigated by monitoring the formation and role of some oxidative species, such as $\mathrm{H}_{2} \mathrm{O}_{2}, \mathrm{O}_{2}{ }^{\bullet-}$ and $\mathrm{OH}^{\bullet}$ radicals.

\section{Experimental}

\subsection{Materials and analysis}

The azo dye acid orange 7 was obtained from Beijing Xuanwu Chemistry Co., and used without further purification. The initial concentration of AO7 was $30 \mathrm{mg} / \mathrm{L}(86 \mu \mathrm{mol} / \mathrm{L})$. Isopropanol $(i$-PrOH) and 1,4-benzoquinone (BQ), which were analytical grade, were purchased from Beijing Chemicals Co, in which BQ was purified by sublimation before used. Catalase (1870 units/mg) from bovine liver was purchased from Sigma Co.

The UV-vis spectra of the samples were recorded from 200 to $650 \mathrm{~nm}$ using a U-3010 UV-vis spectrophotometer (Hitachi Co., Japan). The concentration of the dye was determined by measuring the absorbance at a fixed wavelength $(485 \mathrm{~nm})$ according to the calibration curve established. Total organic carbon (TOC) in solution was measured by a Phoenix 8000 TOC analyzer (Tekmar-Dohrmann Co., USA). Determination of the concentrations of $\mathrm{NO}_{2}{ }^{-}, \mathrm{NO}_{3}{ }^{-}$and $\mathrm{SO}_{4}{ }^{2-}$ ions in solution was accomplished by ion chromatography on a model 4500i (Dionex Corp.) The concentration of $\mathrm{NH}_{4}{ }^{+}$ions in solution was measured by Nesslerization method. The $\mathrm{pH}$ of solution was measured by a model $828 \mathrm{pH}$ meter (Orion Co.). The concentration of ozone in solution was measured by indigo colorimetric method. The concentration of hydrogen peroxide in solution formed during reaction was determined by a colorimetric method [24].

The formation of oxidative species, such as $\mathrm{O}_{2}{ }^{\bullet-}, \mathrm{H}_{2} \mathrm{O}_{2}$ and $\mathrm{OH}^{\bullet}$ radicals, and their role in dye degradation process were investigated by means of appropriate quenchers of these species. Comparisons were made between the original decolorization curves of AO7 solution in MWL and those obtained after addi- tion of quenchers in the initial solution, under otherwise identical conditions. $\mathrm{BQ}, i$-PrOH and catalase were used as the quenchers of $\mathrm{O}_{2}{ }^{\bullet-}, \mathrm{OH}^{\bullet}$ and $\mathrm{H}_{2} \mathrm{O}_{2}$, respectively. The dosages of BQ, $i$ $\mathrm{PrOH}$ and catalase were $0.01 \mathrm{~mol} / \mathrm{L}, 0.01 \mathrm{~mol} / \mathrm{L}$ and $500 \mathrm{mg} / \mathrm{L}$ with referring to other research, respectively [24-26].

\subsection{Degradation procedures}

The microwave source was a domestic microwave oven (Haier. Co. Ltd.; power, $700 \mathrm{~W}$; frequency, $2.45 \mathrm{GHz}$ ). A cylindrical glass reactor (D: $10 \mathrm{~cm} ; \mathrm{H}: 15 \mathrm{~cm}$ ) was employed all through the experiments. Air $\left(0.15 \mathrm{~m}^{3} / \mathrm{h}\right)$ was bubbled through a sintered glass filter fixed at the bottom of the reactor in order to mix the solution. The reactor was placed inside of the erect microwave oven as illustrated in Fig. 1. Solution temperature was kept at $38 \pm 1{ }^{\circ} \mathrm{C}$ by means of circulating solution to a cooler with a peristaltic pump. The whole system was filled with $750 \mathrm{~mL}$ AO7 solution, among which $125 \mathrm{~mL}$ was in the circulation pipe and $625 \mathrm{~mL}$ was in the reactor. MWL, which was made of quartz and filled with mercury and argon, was designed as Ushaped. The UV-vis spectra emitted by the MWL are depicted in Fig. 2. The MWL floated on the solution and about $60 \%$ was immerged in solution.

\subsection{Estimation of the power of the $M W L$}

The power of the MWL could not be measured directly just as conventional lamp. MWL emits UV-vis light by absorbing microwave energy. So, the power of MWL equals to the power of microwave absorbed by it. In this experiment, the power of microwave absorbed by the MWL could be measured by monitoring the temperature of solution and reactor. Microwave irradiation can linearly raise the temperature of the solution and reactor in the initial stage of reaction if the solution is not cooled by circulation. The temperature of the reactor is equal to the temperature of the solution in the reactor. Slope obtained from the straight lines can estimate the microwave power absorbed into the solution and reactor by a means of the following equation $[5]$.

$P=\left(c_{\mathrm{w}} m_{\mathrm{w}}+c_{\mathrm{r}} m_{\mathrm{r}}\right) \frac{\Delta T}{t}$

where $P$ is the power of microwave absorbed by solution and reactor $(\mathrm{W}), m_{\mathrm{W}}$ and $m_{\mathrm{r}}$ masses of water and reactor (water: $750 \mathrm{~g}$, reactor: $680 \mathrm{~g}), c_{\mathrm{W}}$ and $c_{\mathrm{r}}$ the heat capacity of water and reactor (water: $4.184 \mathrm{~J} / \mathrm{g}{ }^{\circ} \mathrm{C}$, reactor: $0.796 \mathrm{~J} / \mathrm{g}{ }^{\circ} \mathrm{C}$ ), $\Delta T$ the temperature rise $\left({ }^{\circ} \mathrm{C}\right)$ and $t$ is the irradiation time (s). When the MWL is inside of the microwave oven and not immerged in water, the power $\left(P_{1}\right)$ absorbed by water and reactor would be lower than the power $\left(P_{2}\right)$ without the MWL in the microwave oven due to MWL absorbing partial microwave energy. $P_{1}$ and $P_{2}$ were 411.9 and $440.0 \mathrm{~W}$ in this system, respectively. It could be calculated that the power of MWL was $28.1 \mathrm{~W}$. During reaction, the power of the MWL was less than $28.1 \mathrm{~W}$ because the power of microwave absorbed by the MWL was reduced because it was partially immerged in solution. 

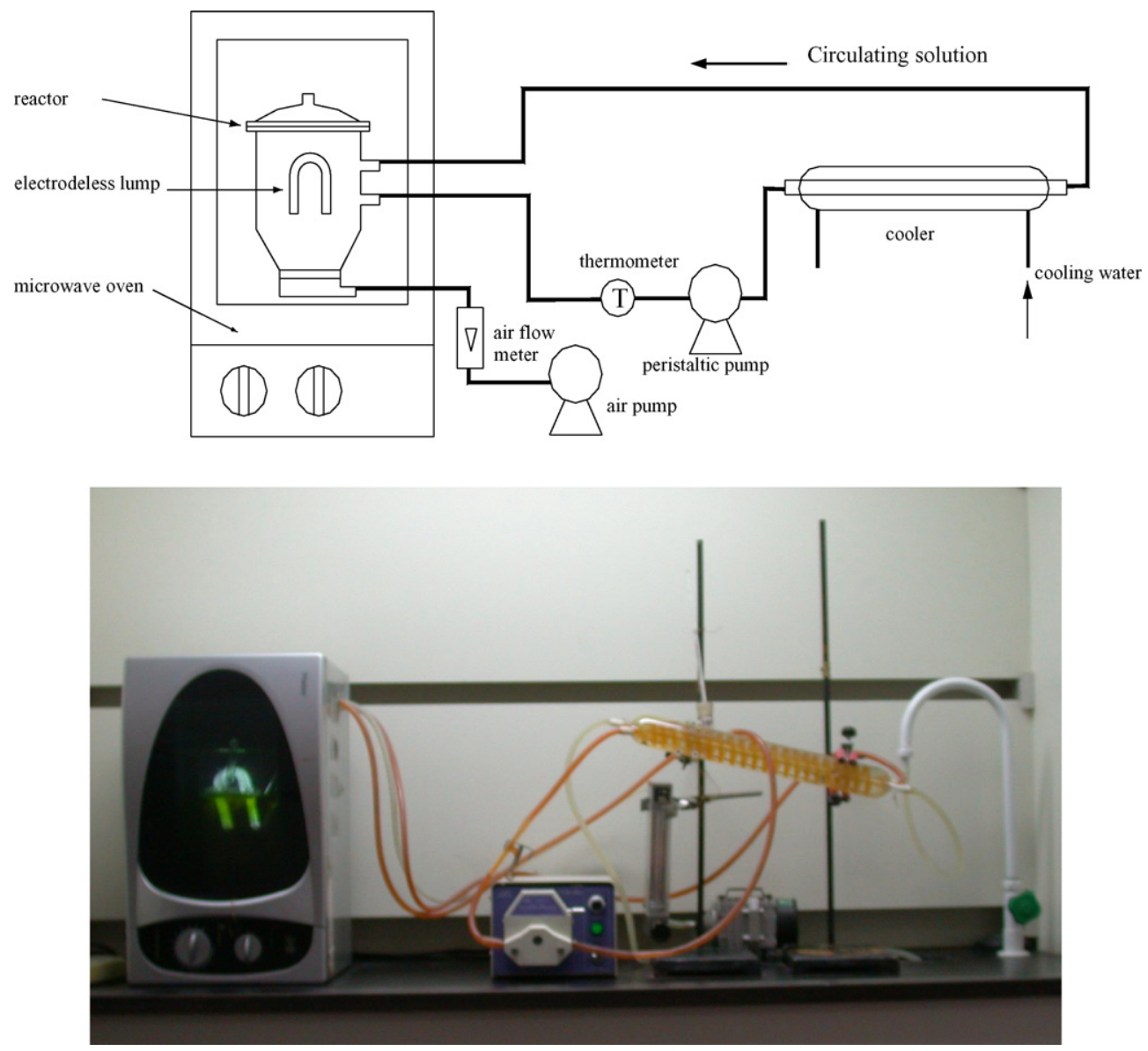

Fig. 1. Experimental setup for MWL photolytic degradation of AO7.

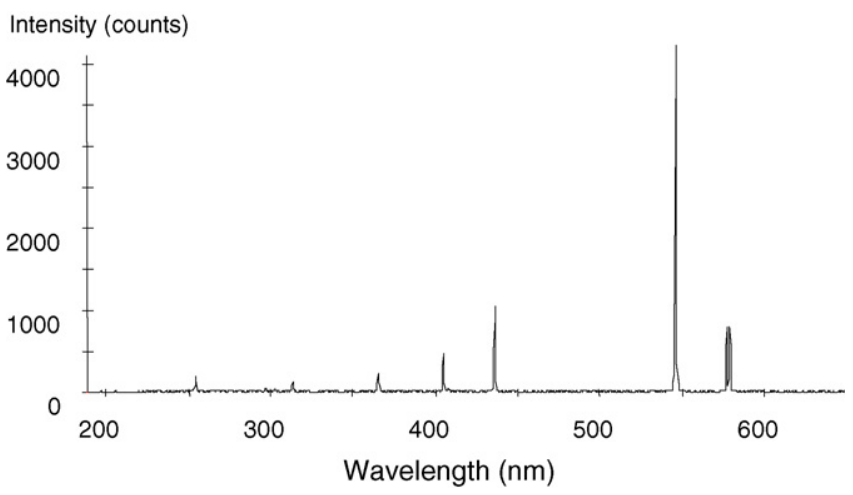

Fig. 2. Emission spectra of MWL.

\section{Results and discussion}

\subsection{UV-vis spectral changes of AO7 solution with irradiation time}

Fig. 3 shows typical UV-vis spectra obtained during MWL photolytic degradation of aqueous solutions of AO7. The spectrum obtained prior to MWL irradiation is characterized by two bands in the visible region, corresponding to the hydrazone form $(485 \mathrm{~nm})$ and azo form $(430 \mathrm{~nm})$ of the dye. These forms originate from intermolecular hydrogen bonding tau- tomeric interactions between the oxygen of the naphthyl group and the $\beta$-hydrogen of the corresponding azo-linkage, respectively [24]. The bands in the ultraviolet region, located at 310 and $228 \mathrm{~nm}$, correspond to the naphthalene and benzene rings of AO7, respectively $[24,27,28]$.

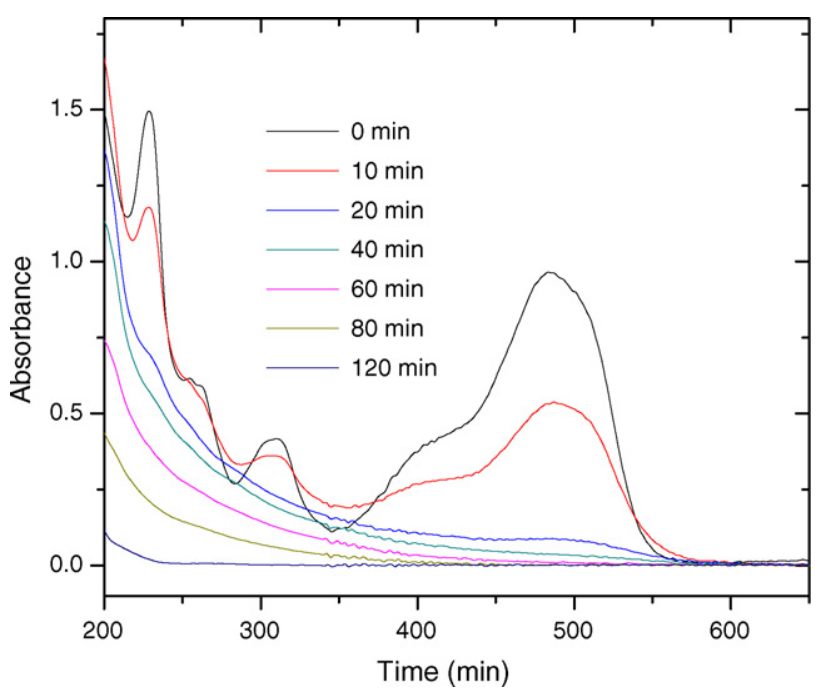

Fig. 3. UV-vis spectral changes of AO7 in solution under MWL irradiation as a function of time of irradiation. 


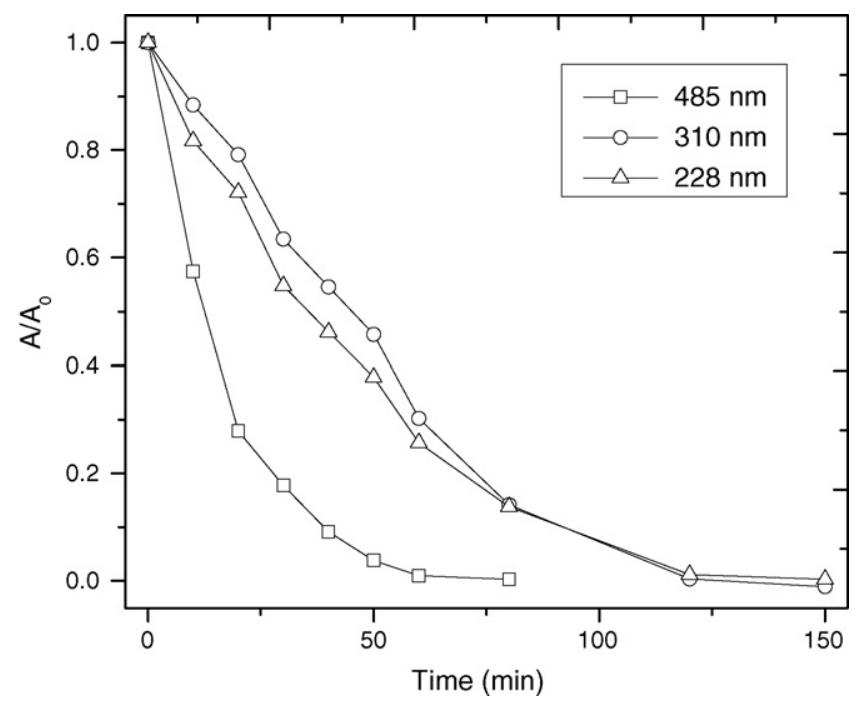

Fig. 4. Normalized absorbance of the main UV-vis bands of AO7 in solution as functions of time of irradiation.

It is observed that MWL has good performance on decolorization of $\mathrm{AO} 7$ from Fig. 3. MWL irradiation caused the absorption bands of the dye in the visible region to decrease with time and finally to disappear at $80 \mathrm{~min}$, resulting in complete decolorization of the solution, which indicates the destruction of its chromophoric structure in the vicinity of the azo-linkage. This was accompanied by the decrease of the intensities of the bands in the ultraviolet region, located at 228 and $310 \mathrm{~nm}$, as Fig. 4 illustrated. The UV-vis spectra of AO7 solution almost disappeared completely after $150 \mathrm{~min}$. This indicates that the destruction of the naphthalene and benzene rings were achieved although it was slower than destruction of azo-linkage. No new absorption bands appeared either in the visible or in the ultraviolet spectral region. The relevant first-order kinetics of the transformation of $\mathrm{AO} 7$ at the three spectral wavelengths, 485,310 and $228 \mathrm{~nm}$, are $7.46 \times 10^{-2}, 2.35 \times 10^{-2}$ and $2.42 \times 10^{-2} \mathrm{~min}^{-1}$, respectively. These data show that the cleavage of azo-linkage is about three-folds faster than these of benzoic and naphthalene rings.

\subsection{Temporal change of $\mathrm{pH}$}

Fig. 5 shows temporal change of pH during MWL degradation in aqueous solutions of AO7. MWL irradiation caused significant decrease of $\mathrm{pH}$ in the period of the initial $100 \mathrm{~min}$, from $\mathrm{pH} 6.15$ at $t=0$ to ca. $\mathrm{pH} 4.12$ at $t=100 \mathrm{~min}$. As has been shown in other study [24], the drop of $\mathrm{pH}$ with time was associated with the formation of acid products by the destruction of dye. However, further illuminating on the bleached solution caused an increase of $\mathrm{pH}$ up to 5.95 at the end of the experiment. This indicates that acid products were further degraded to small molecule substance, ultimately to $\mathrm{CO}_{2}$. The $\mathrm{pH}$ of solution almost reached the initial value before illustration, which also indicates that the $\mathrm{pH}$ change of solution was resulted only from the formation of acid products.

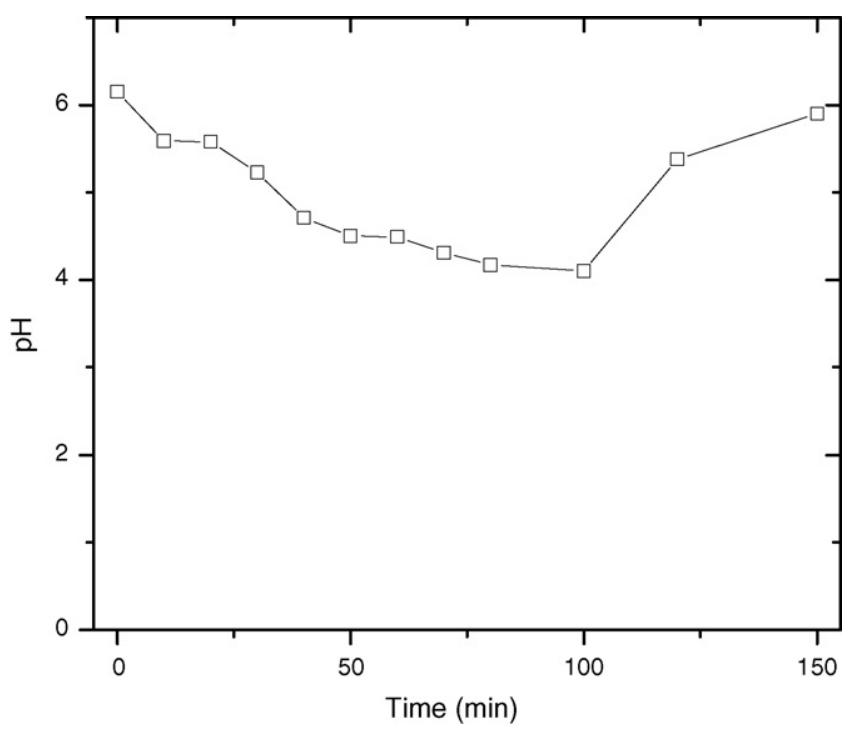

Fig. 5. Change of $\mathrm{pH}$ of the solution under MWL irradiation with time of irradiation.

\subsection{Temporal change of total organic carbon}

Total organic carbon value is the total concentration of organics in solution and the change of TOC mirrors the degree of mineralization as a function of irradiation time. Results of TOC measurements obtained during MWL irradiation treatment of aqueous solution of $\mathrm{AO} 7$ are presented in Fig. 6. It was observed that MWL irradiation had a good performance on mineralization. TOC was completely removed after $150 \mathrm{~min}$ irradiation. Obviously, the mineralization was divided into two stages as shown in Fig. 6. At the first stage (initial $60 \mathrm{~min}$ ), the removal of TOC was very slow and less than $17 \%$ TOC was removed. It could be found from Fig. 4 that the color removal $(485 \mathrm{~nm})$ almost reached $100 \%$ at this stage. However, at the second stage $(60-150 \mathrm{~min})$ when the solution was completely discolored, the TOC removal

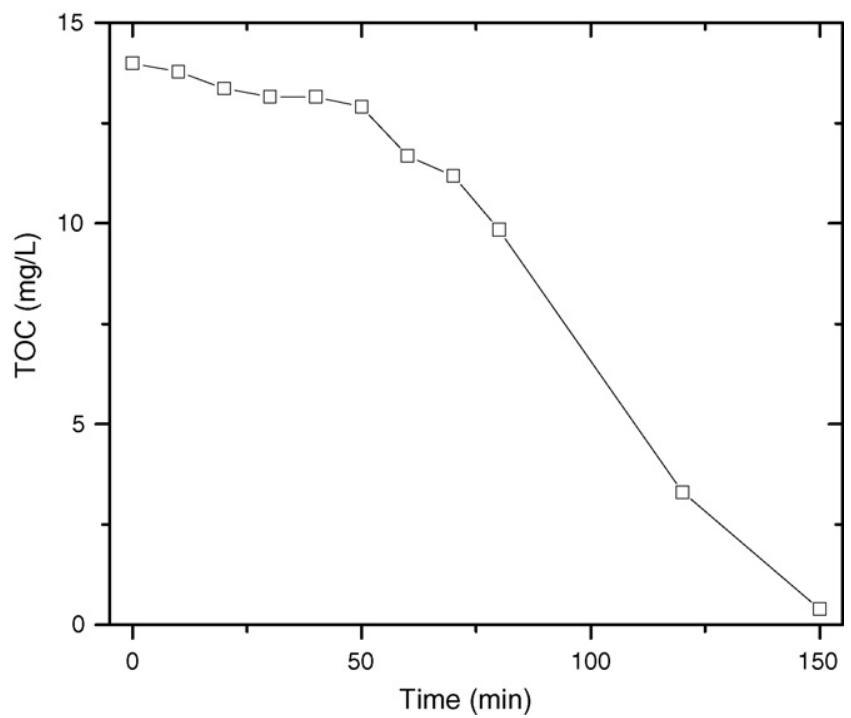

Fig. 6. Change of TOC of the solution under MWL irradiation as function of time of irradiation. 


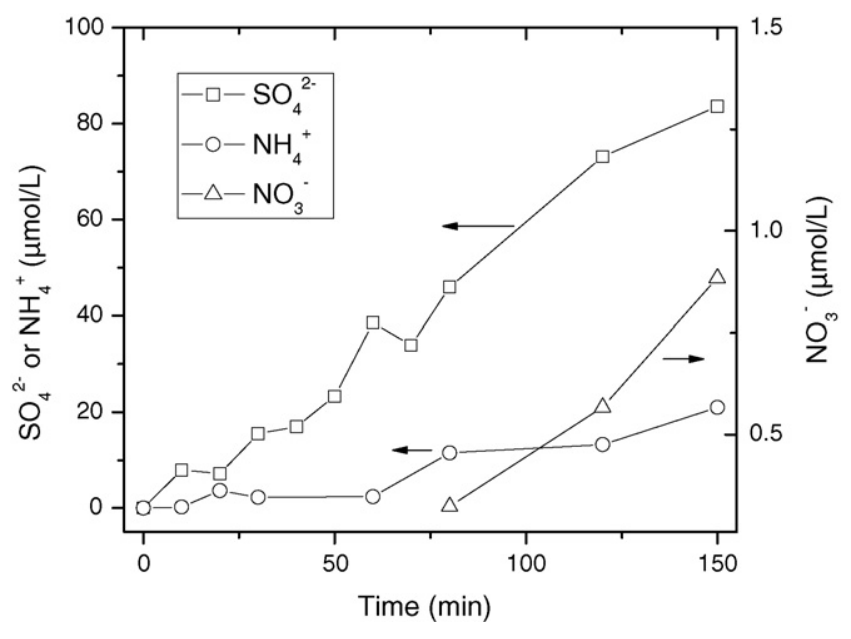

Fig. 7. Concentrations of inorganic ions in solution plotted as functions of time of irradiation.

accelerated remarkably. This phenomenon could be explained as following. At the first stage, most AO7 molecules were only destroyed to small intermediate substances. Subsequently at the second stage these small intermediate substances were further destroyed to $\mathrm{CO}_{2}$ resulting in faster rate of TOC removal.

\subsection{Formation of mineralization products}

The evolution of inorganic ions in solution with time is shown in Fig. 7, where the concentrations of $\mathrm{SO}_{4}{ }^{2-}, \mathrm{NH}_{4}{ }^{+}$and $\mathrm{NO}_{3}{ }^{-}$ are plotted as functions of irradiation time. It was observed that the concentration of sulfate ions increased continuously and reached $83 \mu \mathrm{mol} / \mathrm{L}$ after $150 \mathrm{~min}$ irradiation. This quantity was almost the same as the expected $(86 \mu \mathrm{mol} / \mathrm{L})$ assuming complete mineralization of the dye, which indicates that all sulfonate groups were transformed to $\mathrm{SO}_{4}{ }^{2-}$ under MWL irradiation.

As also observed in Fig. 7, a significant amount of $\mathrm{NH}_{4}{ }^{+}$ions were produced from the initial stage. The formation of $\mathrm{NH}_{4}{ }^{+}$ was slow in the initial $60 \mathrm{~min}$. When the solution was completely discolored after $60 \mathrm{~min}$, the formation of $\mathrm{NH}_{4}{ }^{+}$became fast to some extent. $\mathrm{NO}_{3}{ }^{-}$ions became detectable in solution after $80 \mathrm{~min}$ irradiation. Nitrate ion might be formed by oxidation of nitrite ion which, in turn, was formed by oxidation of ammonium ion $[24,29]$. In this experiment, $\mathrm{NO}_{2}{ }^{-}$was undetectable in the solution during reaction and the concentration of $\mathrm{NO}_{3}{ }^{-}$was 20 times lower than that of $\mathrm{NH}_{4}{ }^{+}$. This indicates that the formation of $\mathrm{NO}_{3}{ }^{-}$from $\mathrm{NH}_{4}{ }^{+}$was very slow. At the end of the experiment, the sum of $\mathrm{NH}_{4}{ }^{+}$and $\mathrm{NO}_{3}{ }^{-}$ions in solution was five times less than that expected from stoichiometry. It may be possible to assume that $\mathrm{N}_{2}$ and/or $\mathrm{NH}_{3}$ were produced and transferred into the gas phase.

Based on the results of above, it can be concluded that MWL photolytic degradation of dye can obtain complete decolorization and mineralization, which is deferent from conventional electrode lamp photolytic degradation. The photolytic degradation of dyes under UV-vis light irradiation alone can also achieve complete decolorization, but it is hardly to obtain mineralization [17-21]. Evidently, the difference of mineralization

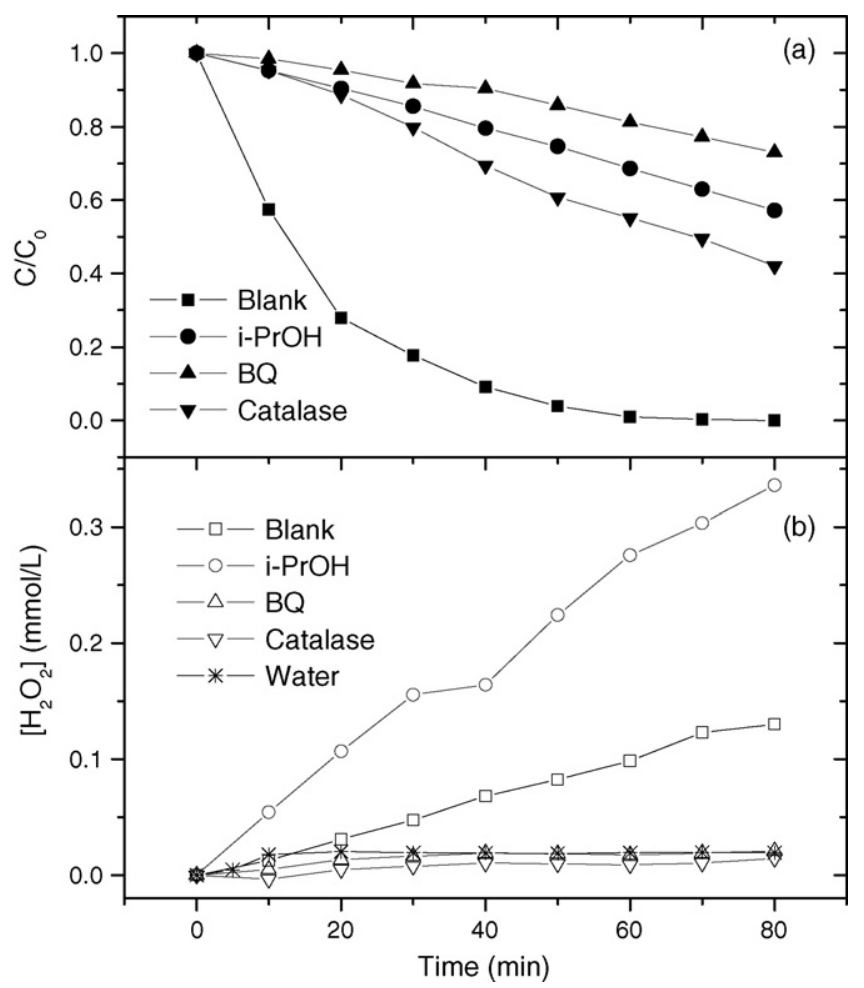

Fig. 8. Variation of normalized dye concentration (a) and $\mathrm{H}_{2} \mathrm{O}_{2}$ concentration (b) in solution in the presence of different quenchers.

between MWL and conventional electrode lamp is caused by the synergetic effect of UV-vis irradiation and microwave irradiation provided by MWL.

\subsection{Formation of oxidative intermediate species}

$i$-PrOH is more easily oxidized by $\mathrm{HO}^{\bullet}$ radicals. The rate constant of reaction between $\mathrm{HO}^{\bullet}$ radical and $i-\mathrm{PrOH}$ is $1.9 \times 10^{9} \mathrm{M}^{-1} \mathrm{~s}^{-1}$, a rate of almost the diffusion limit [25]. So it is usually used as diagnostic tool of $\mathrm{HO}^{\bullet}$ radical. Fig. $8 \mathrm{a}$ shows the inhibitive effect of $0.01 \mathrm{~mol} / \mathrm{L} i-\mathrm{PrOH}$ on decolorization of the dye solution, under otherwise identical experimental conditions. It was observed that in the presence of $i-\mathrm{PrOH}$, photobleaching of $\mathrm{AO} 7$ was suppressed. The apparent rate constant $(k)$ of pseudo-first-order reaction decreased from 0.0746 to $0.0069 \mathrm{~min}^{-1}$. The $90.8 \%$ decrease of $k$ indicates that $90.8 \%$ decolorization of $\mathrm{AO} 7$ under MWL irradiation was achieved by $\mathrm{HO}^{\bullet}$.

The hydrogen peroxide generated in $\mathrm{AO} 7$ solution without quencher under MWL irradiation is shown in Fig. 8b. It was observed that $\mathrm{H}_{2} \mathrm{O}_{2}$ was formed in the solution from the beginning of experiment and its concentration increased continuously with time. $\mathrm{H}_{2} \mathrm{O}_{2}$ acts as a precursor of many reactive species in light-driven reactions [30]. The role of $\mathrm{H}_{2} \mathrm{O}_{2}$ in dye degradation process has been investigated by means of catalase, a quencher of $\mathrm{H}_{2} \mathrm{O}_{2}$ [31,32]. A comparison was made between the original decolorization curves of $\mathrm{AO} 7$ solution and that obtained after addition of catalase $(500 \mathrm{mg} / \mathrm{L})$ in the initial solution. It was observed that decolorization rate decreased markedly and the $k$ was $0.0104 \mathrm{~min}^{-1}$, which decreased $86.1 \%$. This indi- 
cated that $\mathrm{H}_{2} \mathrm{O}_{2}$ played an important role in MWL photolytic degradation of $\mathrm{AO} 7$. The decolorization of $\mathrm{AO} 7$ by the direct oxidation by $\mathrm{H}_{2} \mathrm{O}_{2}$ was negligible due to low reaction rate [20]. Evidently, other pathways rather than direct reaction with $\mathrm{AO} 7$ were involved for the degradation of $\mathrm{AO} 7$ by $\mathrm{H}_{2} \mathrm{O}_{2}$. As discussed above, $\mathrm{HO}^{\bullet}$ was the main oxidative species leading to decolorization of AO7. Therefore, it was concluded that $\mathrm{H}_{2} \mathrm{O}_{2}$ took part in decolorization of $\mathrm{AO} 7$ by generation of $\mathrm{HO}^{\bullet}$ as its precursor according to the following reaction $[33,34]$ :

$\mathrm{H}_{2} \mathrm{O}_{2}+h v \rightarrow 2 \mathrm{HO}^{\bullet}$

Fig. 8 shows that the effect of addition of $0.01 \mathrm{~mol} / \mathrm{l} \mathrm{BQ}$ on the decolorization of dye solution and $\mathrm{H}_{2} \mathrm{O}_{2}$ generation. It was observed that in the presence of $\mathrm{BQ}$, which is a $\mathrm{O}_{2}{ }^{\bullet-}$ quencher, both photobleching of $\mathrm{AO} 7$ and formation of $\mathrm{H}_{2} \mathrm{O}_{2}$ were suppressed. The $k$ was only $0.0046 \mathrm{~min}^{-1}$, which decreased by 93.8\%. The amount of $\mathrm{H}_{2} \mathrm{O}_{2}$ in $\mathrm{AO} 7$ solution was largely less than that in the absence of BQ. This indicated that the superoxide radical was an important intermediate, which generated $\mathrm{H}_{2} \mathrm{O}_{2}$ and ultimately generated $\mathrm{HO}^{\bullet}$. Cooper et al. [35] also proved that hydrogen peroxide appears to result from the disproportionation of $\mathrm{O}_{2}{ }^{\bullet-}$.

$\mathrm{O}_{2}^{\bullet-}+\mathrm{H}^{+} \rightarrow \mathrm{HO}_{2}^{\bullet}$

$\mathrm{HO}_{2}^{\bullet}+\mathrm{O}_{2}^{\bullet-}+\mathrm{H}^{+} \rightarrow \mathrm{H}_{2} \mathrm{O}_{2}+\mathrm{O}_{2}$

$\mathrm{HO}_{2}^{\bullet}+\mathrm{e}^{-}+\mathrm{H}^{+} \rightarrow \mathrm{H}_{2} \mathrm{O}_{2}$

The formation of $\mathrm{H}_{2} \mathrm{O}_{2}$ in pure water under MWL irradiation was different from that in $\mathrm{AO} 7$ solution as shown in Fig. 8b. The concentration of $\mathrm{H}_{2} \mathrm{O}_{2}$ in pure water reached the maximal value $(0.029 \mathrm{mmol} / \mathrm{L})$ at $10 \mathrm{~min}$ and subsequently decreased slightly. However, 4.5 times higher concentration of $\mathrm{H}_{2} \mathrm{O}_{2}$ was observed in $\mathrm{AO} 7$ solution under MWL irradiation at $80 \mathrm{~min}$ with under otherwise identical conditions, reaching $0.13 \mathrm{mmol} / \mathrm{L}$. It can be concluded that most $\mathrm{H}_{2} \mathrm{O}_{2}$ formed in $\mathrm{AO} 7$ solution under MWL irradiation were related to $\mathrm{AO} 7 . \mathrm{O}_{2}^{\bullet-}$, the precursor of $\mathrm{H}_{2} \mathrm{O}_{2}$, could be formed by the reduction of oxygen in solution where the light-absorbing substances (dissolved organic matter (DOM)) either generate free electrons by photoionization or reduce oxygen by energy transfer from the exited state $[35,36]$.

$$
\begin{aligned}
& \mathrm{DOM}^{+} h v \rightarrow \mathrm{DOM}^{*} \\
& \mathrm{DOM}^{*} \rightarrow \mathrm{DOM}^{\bullet+}+\mathrm{e}^{-} \\
& \mathrm{DOM}^{\bullet+}+\mathrm{e}^{-} \rightarrow \mathrm{DOM}^{\bullet+}+\mathrm{e}_{\mathrm{aq}}- \\
& \mathrm{DOM}^{*}+h v \rightarrow \mathrm{DOM}^{\bullet+}+\mathrm{e}_{\mathrm{aq}}{ }^{-} \\
& \mathrm{e}_{\mathrm{aq}}{ }^{-}+\mathrm{O}_{2} \rightarrow \mathrm{O}_{2}^{\bullet-}
\end{aligned}
$$

It was proved that the dye molecules could be excited by visible light photons to produce singlet and/or triplet states [24,37]. Therefore, $\mathrm{H}_{2} \mathrm{O}_{2}$ could be generated by $\mathrm{AO} 7$ absorbing light according to the series of reactions as shown above. It was found that $\mathrm{H}_{2} \mathrm{O}_{2}$ did not disappear immediately when the solution was decolorized completely at $80 \mathrm{~min}$. The concentration of $\mathrm{H}_{2} \mathrm{O}_{2}$ decreased gradually after $80 \mathrm{~min}$ and was close to the value in pure water when TOC was removed completely at $150 \mathrm{~min}$ (not shown). This implied that the intermediate products during degradation of $\mathrm{AO} 7$ also had the ability to generate $\mathrm{H}_{2} \mathrm{O}_{2}$ as light-absorbing substances. It was consistent with what was found by Cooper et al. [35] that many DOM in surface water and ground water could be exited by light to produce $\mathrm{H}_{2} \mathrm{O}_{2}$. The larger amount of $\mathrm{H}_{2} \mathrm{O}_{2}$ generated in the presence of isopropyl alcohol was also attributed to more DOM in the solution after addition of isopropyl alcohol.

As shown above, the $k\left(0.0069 \mathrm{~min}^{-1}\right)$ in the presence of $\mathrm{HO}^{\bullet}$ quencher, $i$-PrOH, was lower than that $\left(0.0104 \mathrm{~min}^{-1}\right)$ in the presence of $\mathrm{H}_{2} \mathrm{O}_{2}$ quencher, catalase, indicating that there was other precursors of $\mathrm{HO}^{\bullet}$ besides $\mathrm{H}_{2} \mathrm{O}_{2}$. It was doubtless that ozone was generated in the solution under MWL irradiation because odor of ozone was smelled during reaction. Ozone could be generated according the following reaction [36]:

$\mathrm{O}_{2}+h v(<242 \mathrm{~nm}) \rightarrow 2 \mathrm{O}$

$\mathrm{O}+\mathrm{O}_{2} \rightarrow \mathrm{O}_{3}$

The concentration of ozone in solution after $30 \mathrm{~min}$ MWL irradiation was measured by indigo colorimetric method. Its concentration was $0.12 \mu \mathrm{mol} / \mathrm{L}$. $\mathrm{HO}^{\bullet}$ could be generated by the decomposition of ozone in solution by Eqs. (13) and (14) [38].

$\mathrm{O}_{3}+h v(<310 \mathrm{~nm}) \rightarrow \mathrm{O}^{\bullet}+\mathrm{O}_{2}$

$\mathrm{O}^{\bullet}+\mathrm{H}_{2} \mathrm{O} \rightarrow 2 \mathrm{HO}^{\bullet}$

According to (the) discussion above, the main pathway of oxidative species under MWL irradiation could be summarized as shown in Fig. 9.

The first-order apparent rate constants $(k)$ of the decolorization in the presence of these quenchers are listed in Table 1. The contribution of $\mathrm{HO}^{\bullet}, \mathrm{H}_{2} \mathrm{O}_{2}$ and $\mathrm{O}_{2} \bullet-$ to the decolorization of $\mathrm{AO} 7$ was $90.8,86.1$ and $93.8 \%$ according to their decrease percentages of $k$, respectively. The contribution of $\mathrm{H}_{2} \mathrm{O}_{2}$ was completely achieved by generating $\mathrm{HO}^{\bullet}$ to oxidize $\mathrm{AO} 7$ because its direct oxidation was negligible as discussed above. That is, the contribution of $\mathrm{HO}^{\bullet}$ resulted from $\mathrm{H}_{2} \mathrm{O}_{2}$ equaled that of $\mathrm{H}_{2} \mathrm{O}_{2}$ and was also $86.1 \%$. It was presumed that other precur-

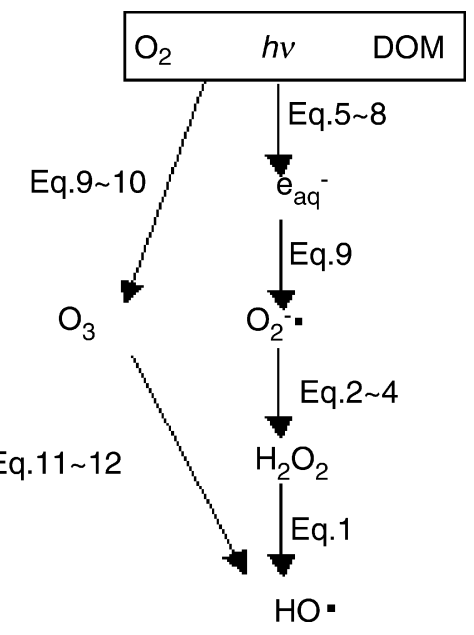

Fig. 9. Reaction pathways of oxidative species in AO7 solution under MWL irradiation. 
Table 1

The first-order apparent rate constants $(k)$ of the decolorization in the presence of $I-\mathrm{PrOH}$, catalase and BQ

\begin{tabular}{lllll}
\hline Quenchers & Blank & $i$-PrOH & Catalase & BQ \\
\hline$k\left(\min ^{-1}\right)$ & 0.0746 & 0.0069 & 0.0109 & 0.0046 \\
Decrease percentage of $k$ & - & $90.8 \%$ & $86.1 \%$ & $93.8 \%$ \\
\hline
\end{tabular}

sors of $\mathrm{HO}^{\bullet}$ were negligible besides $\mathrm{H}_{2} \mathrm{O}_{2}$ and $\mathrm{O}_{3}$. Therefore, It could be calculated that the contribution of $\mathrm{HO}^{\bullet}$ resulted from $\mathrm{O}_{3}$ was $4.7 \%$ by subtracting the contribution of $\mathrm{HO}^{\bullet}$ resulted from $\mathrm{H}_{2} \mathrm{O}_{2}$ from the total contribution of $\mathrm{HO}^{\bullet}$. The contribution of $\mathrm{H}_{2} \mathrm{O}_{2}$ to the formation of $\mathrm{HO}^{\bullet}$ was 18 times higher than that of $\mathrm{O}_{3}$. However, the concentration of $\mathrm{H}_{2} \mathrm{O}_{2}$ was approximately 500 times higher than the concentration of $\mathrm{O}_{3}$ at $30 \mathrm{~min}$. Formation and decomposition of $\mathrm{H}_{2} \mathrm{O}_{2}$ and $\mathrm{O}_{3}$ were simultaneous during reaction [31]. The reason why lower concentration of ozone was observed was that the decomposition rate of ozone was much higher than that of $\mathrm{H}_{2} \mathrm{O}_{2}$, approaching its formation rate. The molar extinction coefficient of ozone at $254 \mathrm{~nm}$ is $3300 \mathrm{M}^{-1} \mathrm{~s}^{-1}$, compared with $19.6 \mathrm{M}^{-1} \mathrm{~s}^{-1}$ of $\mathrm{H}_{2} \mathrm{O}_{2}$ [5].

The contribution $(93.8 \%)$ of $\mathrm{O}_{2}{ }^{--}$to decolorization was higher than that $(86.1 \%)$ of $\mathrm{H}_{2} \mathrm{O}_{2}$, which indicated that $7.7 \%$ decolorization of $\mathrm{AO} 7$ was resulted from the effect of $\mathrm{O}_{2}{ }^{\bullet-}$ by other pathways rather than by forming $\mathrm{H}_{2} \mathrm{O}_{2}$. Although $\mathrm{O}_{2}{ }^{\bullet-}$ and its hydroperoxyl radical $\left(\mathrm{HO}_{2}{ }^{\bullet-}\right)$ are generally considered as a weak oxidant, they might react with $\mathrm{AO} 7$ directly. Ryu and Choi [39] also recently confirmed that $\mathrm{O}_{2}{ }^{\bullet-}$ was mainly responsible for the oxidation of As by photocatalysis. The $k$ in the presence of $\mathrm{O}_{2}{ }^{\bullet-}$ quencher was only $6.2 \%$ of the $k$ in the absence. The oxidative species in solution in the presence of $\mathrm{O}_{2}{ }^{\bullet-}$ quencher were mainly $\mathrm{O}_{3}$ and $\mathrm{HO}^{\bullet}$ from the decomposition of $\mathrm{O}_{3}$. That is, $6.2 \%$ decolorization of $\mathrm{AO} 7$ was achieved by $\mathrm{O}_{3}$ and $\mathrm{HO}^{\bullet}$ from the decomposition of $\mathrm{O}_{3}$. The contribution of $\mathrm{O}_{3}$ to the decolorization of $\mathrm{AO} 7$ by direct oxidation was $1.5 \%$ because the contribution of $\mathrm{HO}^{\bullet}$ from the decomposition of $\mathrm{O}_{3}$ was $4.7 \%$ as discussed above.

\section{Conclusion}

MWL had excellent performance on decolorazition and mineralization of $\mathrm{AO} 7$. Complete decolorization and mineralization were achieved at 80 and $150 \mathrm{~min}$, respectively. Sulfonate groups were completely transformed into $\mathrm{SO}_{4}{ }^{2-}$ and azo-linkages were transformed into $\mathrm{N}_{2}, \mathrm{NH}_{3}, \mathrm{NH}_{4}{ }^{+}$and $\mathrm{NO}_{3}{ }^{-}$. The better performance on mineralization of $\mathrm{AO} 7$ solution under MWL irradiation than that under conventional electrode lamp irradiation was caused by the synergic effect of UV-vis light and microwave. A large mount of $\mathrm{H}_{2} \mathrm{O}_{2}$ and $\mathrm{O}_{3}$ could be generated in $\mathrm{AO} 7$ solution under MWL irradiation. These $\mathrm{H}_{2} \mathrm{O}_{2}$ and $\mathrm{O}_{3}$ could produce lots of $\mathrm{HO}^{\bullet}$ radicals by decomposition under light irradiation to degrade $\mathrm{AO} 7$ dyes effectively.

\section{Acknowledgements}

The authors appreciate the generous financial support of this work by the Chinese found 863 project (2002AA601300) and thank to Wuhan University of Science \& Engineering for their help in the experiment.

\section{References}

[1] S. Kataoka, D.T. Tompkins, W.A. Zelter, M.A. Anderson, J. Photochem. Photobiol. A: Chem. 148 (2002) 323-330.

[2] S. Caddick, Tetrahedron 51 (1995) 10403-10432.

[3] S. Horikoshi, H. Hidaka, N. Serpone, Environ. Sci. Technol. 36 (2002) 1357-1366.

[4] V. Círka, M. Hájek, J. Photochem. Photobiol. A: Chem. 123 (1999) 21-23.

[5] D.H. Han, S.Y. Cha, H.Y. Yang, Water Res. 38 (2004) 2782-2790.

[6] S. Horihoshi, H. Hidaka, N. Serpone, J. Photochem. Photobiol. A: Chem. 153 (2002) 185-189.

[7] S. Horihoshi, H. Hidaka, N. Serpone, Environ. Sci. Technol. 36 (2002) 5229-5237.

[8] S. Horihoshi, H. Hidaka, N. Serpone, J. Photochem. Photobiol. A: Chem. 159 (2003) 289-300.

[9] S. Horihoshi, A. Saitou, H. Hidaka, N. Serpone, Environ. Sci. Technol. 37 (2003) 5813-5822.

[10] S. Horihoshi, H. Hidaka, N. Serpone, J. Photochem. Photobiol. A: Chem. 161 (2004) 221-225.

[11] S. Horihoshi, A. Tokunaga, H. Hidaka, N. Serpone, J Photochem. Photobiol. A: Chem. 162 (2004) 33-42.

[12] P. Klán, J. Literák, M. Hájek, J. Photochem. Photobiol. A: Chem. 128 (1999) 145-149.

[13] J. Literák, P. Klán, J. Photochem. Photobiol. A: Chem. 137 (2000) 29-35

[14] P. Müller, P. Klán, V. Církva, J. Photochem. Photobiol. A: Chem. 158 (2003) 29-35.

[15] A. Bianco-Prevot, C. Baiocchi, M.C. Brussino, E. Pramauro, P. Savarino, V. Augugliaro, G. Marci, L. Palmisano, Environ. Sci. Technol. 35 (2001) 971-976.

[16] B. Neppolian, H.C. Choi, S. Sakthivel, B. Arabindoo, V. Murugesan, Chemosphere 46 (2002) 1173-1181.

[17] Y. Xu, Chemosphere 43 (2001) 1103-1107.

[18] J. Bandara, J. Kiwi, New J. Chem. 23 (1999) 717-724.

[19] M. Muruganadham, M. Swaminathan, Dyes Pigments 63 (2004) $315-$ 321.

[20] M.A. Behnajady, N. Modirshahla, Chemosphere 55 (2004) 129134.

[21] A.M. Ei-Dein, J.A. Libra, U. Wiesmann, Chempsphere 52 (2003) 1069-1077.

[22] X. Zhang, Y. Wang, G. Li, J. Mol. Catal. A: Chem. 237 (2005) 199_ 205.

[23] X. Zhang, Y. Wang, J. Hazard. Mater., in press.

[24] M. Strylidi, D. Kondarides, X. Verykios, Appl. Catal. B: Environ. 47 (2004) 189-201.

[25] Y. Chen, S. Yang, K. Wang, L. Lou, J. Photochem. Photobiol. A: Chem. 172 (2005) 47-54.

[26] S. Malato, J. Blanco, J. caceres, A.R. Fernández-Alba, A. Agüera, A. Rodríguez, Catal. Today 76 (2002) 209-220.

[27] M. Strylidi, D. Kondarides, X. Verykios, Appl. Catal. B: Environ. 40 (2003) 271-286.

[28] F. Wu, N. Deng, H. Hua, Chemosphere 41 (2000) 1233-1238.

[29] G. Low, S. Mcevoy, R. Matthews, Environ. Sci. Technol. 25 (1991) 460-467.

[30] R.L. Ziolli, W.F. Jardim, J. Photochem. Photobiol. A: Chem. 147 (2002) 205-212.

[31] T. Wu, G. Liu, J. Zhao, H. Hidaka, N. Serpone, J. Phys. Chem. B 103 (1999) 4862-4867.

[32] E. Pelizzetti, C. Minero, Colloids Surf. A: Physicochem. Eng. Aspects 151 (1999) 321.C-327.C

[33] C.C. Wong, W. Chu, Environ. Sci. Technol. 37 (2003) 23102316.

[34] D.D. Dionysiou, M.T. Suidan, E. Bekou, I. Baudin, J.M. Laîné, Appl. Catal. B: Environ. 26 (2000) 153-157. 
[35] W. Cooper, R. Zlka, R. Petasne, J. Plane, Environ. Sci. Technol. 22 (1988) $1156-1160$.

[36] N. Deng, F. Wu, Environmental Photochemistry, Chemistry Industry Publishing Company, Beijing, 2003.

[37] J.C. Zhao, T.X. Wu, K. Wu, K. Oikawa, H. Hidaka, N. Serpone, Environ. Sci. Technol. 32 (1998) 2394-2400.
[38] P. Zhang, F. Liang, G. Yu, Q. Chen, W. Zhu, J. Photochem. Photobiol. A: Chem. 156 (2003) 189-194.

[39] J. Ryu, W.Y. Choi, Effects of $\mathrm{TiO}_{2}$ surface modifications on photocatalytic oxidation of arsenite: the role of superoxide, Environ. Sci. Technol. 38 (2004) 2928-2933. 